\title{
Efficacy of the Cognitive and Exposure Therapy in the Treatment of Obsessive-Compulsive Disorder
}

\author{
Hiva Mahmoodi ${ }^{1, *}$, Hasan Gharibi ${ }^{1}$, Mohamad Khaledian ${ }^{3}$ \\ ${ }^{1}$ Faculty of Psychology and Educational Sciences, Saqhez Branch, Islamic Azad University, \\ Saqhez, Iran \\ ${ }^{2}$ Faculty of Psychology and Educational Sciences, Ghorveh Branch, Islamic Azad University, \\ Ghorveh, Iran
}

*E-mail address: Hiva_224@yahoo.com

\begin{abstract}
The aim of this study was the investigation of the efficacy of the Cognitive and Exposure therapy on the treatment of obsessive- compulsive disorder. This study is experimental expanded with multiple group pre-test, post-test. The statistical population of this study are included all patients with OCD, referred to clinical centers, hospitals and private clinics and counseling centers in Saghez and Boukan citiesat the age of 40-20 years. The statistical sample of this study is included 45 patientswith Obsessive Compulsive Disorder, Who were selected randomly. Cognitive therapy was administered for the first experimental group and the second experimental group receives exposure therapy while the control group received no treatment. Subscales Madsly questionnaire was usedfor data gathering for OCD. For data analysis, multivariate analysis of covariance (MANCOVA) and least significant difference test to compare scores differences between pretest - posttest variables in the experimental and control groups was used. Findings showed that Cognitive and Aversion Therapy on the control group has a significant impact on the improvement of obsession, check out, washing, slowness and obsessive doubts. The results showed that Whittal Cognitive Therapy more impact on the reduction of obsessions in comparsion with Exposure therapy.
\end{abstract}

Keywords: Cognitive therapy; Exposure therapy; Obsessive-Compulsive Disorder

\section{INTRODUCTION}

Obsessive-Compulsive Disorder is characterized by obsessions and compulsion which creates distress and often interferes in a daily performance. Obsessions are thoughts or impulses that do not have meaning for a person. Compulsions are intentional repetitive behaviors or mental acts that occur in response to obsessions. Ceremonial activities (Such as washing to eliminate pollution and Checkout to end the fear of a horror incident) are often directly related to obsessive anxiety (Rachman \& DE Silva, 2004). Gathering or Hoarding of objects including written information (newspapers, magazines, documents and bills)in order to prevent loss of information or objects that might be important is a kind of ceremonial. Another type of ceremonial behavior is repeated counting. Other forms of compulsive behaviors are repeated requests for reassurance from their family members, For example, too much control is to ensure child health (Van Oppen, Emmelkamp, van Balkom A \& van Dyck, 2005). Prevalence of OCD in the general population is believes to be $0 / 5$ percent. However, epidemiological studies have shown a prevalence of $2 / 5$ percent. Obsessions, men and women are almost equally affected. Typically, the onset of disorder is in late adolescence or early twenties (America Psychiatric Association, 2000). In order to treat this disorder, various 
methods have been conducted including Drug therapy, Family Therapy, Group Therapy, Electric Shock Therapy, Behavior Therapy and Cognitive - Behavioral Therapy. Cognitive methods have also been used recently in the treatment of OCD that Suggesting cognitive components involved in this disorder (Pinard, 2008). Cognitive theoreticians believe that people with OCD have difficulty in the ability to organize and integrate information. They are impaired in response to emotional stimuli and their processing and thoughts are misused insuch a way that they are appeared in the form of obsessions (Veale, 2007). One cognitive explanation obsession is that people suffering from OCD, have unusual expectations about negative thoughts (For example, they think that if they handle of containers of waste, they become sick and die). Moreover, they exagerated negative consequences of various actions (For example, if you start to feel lost when driving, or the disks will encounter something, they think they have struck someone) (Wells \& Hatton, 2004). Some cognitive theoreticians believe that unwanted and intrusive common thoughts are change into obsessive thoughts when the person interruptions and unwanted will evaluate them as traumatic and damaging and thinks he is responsible.

This assessment leads to increased anxiety and guilt and consequently, person startsavoidance behaviors to reduce anxiety. Treatment is focused on identifying and modifying negative thoughts, modified attitudes related to extreme responsibilities, increase exposure and reduce avoidance behaviors (Gunter and Whittal, 2010). Whittal (2009) believes that cognitive therapy is an effective strategy for improving social functioning and depression in patients with OCD. Whittal, Woody and Rachman (2009) conducted a research with thetitleof effects of cognitive therapy on obsessive thoughts. The cognitive therapy group was compared with control group and stress management training group. The therapy was conducted on 68 patients and they were followed for one year; Results showed that cognitive therapy and stress management training had a significant impact on reducing symptoms of obsessive thoughts. Also, the results showed that cognitive therapy is better than the management education therapy. Whittal, Robichaud and Woody (2010) conducted a research with the title of cognitive therapy for obsessive thoughts; some of the key dimensions of cognitive therapy are trained. The results showed that these key elements are effective in reducing obsessive thoughts. Bellocha and Cabedob (2010) conducted a study entitled Cognitive therapy for obsessive thoughts spontaneously after a one year follow-up. Results showed that cognitive therapy had been a significant impact on the reduction of spontaneous thoughts. Whittal and Sheila (2010) conducted a study entitled Cognitive therapy for patients with obsessive thoughts on samples of 67 individuals who had suffered from obsessive thoughts, Results showed that after 12 months of continuous therapy followup, these thoughts have been reduced to 65 percent. Whittal and Sheila (2010) in another study entitled cognitive therapy for obsessive thoughts showed that cognitive therapy helps to control obsessive thoughts and causes them do less ceremonial behaviors (compulsions). Also Psychoanalytic Association of America (2000) showed that behavioral therapy "Exposure and Response Prevention "is the established therapy for obsessive - compulsive disorder. Variables involved in Exposure and Response Prevention therapy include areIn Vivo Exposure: To situate patient's in real life, which is the circumstance suffer anxiety and launches his obsessive behavior.

The second one is Response Prevention: Prevent the obsessive behavior.The third one is Imaginary Exposure: This style is used when the patient cannot be placed in real-life situations. Based on clinical experience of Foa and colleagues (2000) exposed imaginary obsession is helpful for patients since it creates an opportunity for the patient to exposure with their fears. Furthermore, adding an Imaginary Exposure to In Vivo Exposure can cover the patient's cognitive avoidance strategies. The next variable is Gradual exposure versus severe exposure: There is no difference between the two methods, but gradual exposure is better since will maintain patient motivation and cooperation and Exposure time is the next variable: 
Prolonged continuous exposure is more effective than short-term intermittent exposure. Studies have shown that continuous exposure is required for approximately 90 minutes to reduce anxiety. If the anxiety dose not decrease, exposure should be continued more than 90 minutes that has shown results daily sessions.

The last variable is Sessions of Exposure: Intensive exposure therapy session should be continued for one month (Abramowitz, 2006). Foa \& Kozak (2003) showed that with exposure and response prevention, 83 percent of patients improved slightly.Foa \&Kozak (2003) compared Drug therapy to Exposure and Response Prevention. Drug therapy reduces anxiety and depression, but doesnot have much effect on OCD symptoms. Franklin, \& Foa (2005) concluded that inhibition of the response to therapy and exposure therapy is the best treatment for obsessive - compulsive disorder.Merlo and Duke(2007) reported that if cognitive method combines with behavioral techniques, they will have a better impact on the therapy obsessions. In a Meta-Analysis, Abramowitz (2006) concluded that exposure based on therapist guidelines is better than self controlled exposure. Furthermore, adding a Visual Exposure to Vivo Exposure improves anxiety symptoms in obsessions. Wan Open et al (2005) compared the effects of cognitive therapy with self- control exposure as well as inhibition of the response in OCD symptoms. Another aim of the research was to compare the effects of six sessions of cognitive therapy with 6 sessions of exposure and response inhibition, the results showed that both therapies were significantly improving.

Analysis of variance suggested that cognitive therapy is more effective than exposure therapy in obsessions symptoms and the effect of cognitive therapy was more than exposure therapy. Whittal, Thorderson \& Mclean (2005) compared the effectiveness of cognitive behavior therapy and exposure and response prevention on patients with obsessive compulsive. Improvement in patients who had received CBT is 67 percent and in patients who were treated with exposure and response prevention is 59 percent. Also, research has shown that current methods cannot be very effective in the treatment of obsessions. Therefore, it is likely to cause more severe psychological problems (e.g major depression) and consequently more time and money is spent (Woody, 2003). On the other hand, this study sought to examine this hypothesis that the efficacy of Whittal cognitive therapy versus exposure therapy is different in OCD symptoms.

\section{METHOD}

This study is experimental expanded with multiple group pre-test, post-test. The statistical population of this study are included all patients with OCD, Referred to clinical centers, hospitals and private clinics and counseling centers in Saghez and Boukan cities at the age of range 40-20 years. The statistical sample of this study is included 45 patients with Obsessive Compulsive Disorder, Who were selected randomly. After taking the initial characteristics of the patients to detect OCD, Madsly Obsessive Compulsive Questionnaire was used to identify the type of obsessions. By using clinical interviews, co morbidity patients with depression and anxiety were removed. After evaluation, the subjects were replaced randomly divided in the three groups (Whittal group cognitive therapy, exposure therapy and a control group). At the end of therapy sessions, Madsly questionnaire was completed again for obsessions symptoms as post-tests for each of the three groups of subjects. Whittal cognitive therapy group composed of 10 session's for 50 to $60 \mathrm{~min}$ and exposure therapy group composed of 10 session's for $60 \mathrm{~min}$. 


\section{Instrument}

Scale of obsessive- compulsive Madsly: The questionnaire by Rachman and Haj son (1980) has been prepared in order to study the obsessions types. The questionnaire is consists of 30 correct - wrong questions. Scores range is Variable from zero to thirty. In addition to the obsession total score, Madlsy questionnaire includes four subscales check out, washing, slowness and obsessive doubts. The convergent validity and reliability of test - retest has been reported 0/89 and 0/90 by Rachman and Hajson (1980).

\section{Intervention}

Whittal Cognitive Therapy: First Session: Collect information related to obsessive thoughts, compulsive acts, the general history of patient, talking about the patientmood, his/ her feeling during the obsessive ceremonial, Planning therapy program and Motivation for therapy. Second session: Regular home assignmentswere givenin order to review and record of obsessive thoughts and concerns. Frequently review include: Notes obsessive thoughts, diary notes of compulsive behaviors, and other obsessive behaviors and the desire to neutralize the anxiety and discomfort ratings. Session Third session: patient is faced with a list of thoughts reported by normal subjects and the patient will be asked to determine a disturbing think that create anxiety (E.g. having to drive on the edge of the bridge). If unwanted thoughts evaluations were believed to be meaningless provide a basis for subsequent therapy. The aim of these session treatment is to achieve differentiation between unwanted thoughts and assessment skills. This method was used to detect disturbing thoughts, modified of negative evaluation, interfering thoughts and sense of responsibility extreme, the challenge of combine thought - Action, lack hidden obsessions (Especially to share it with people who hide their thoughts) and encourage the patient to express his thoughts more easily. Four to eight Sessions: each Session is divided into three parts, the first part will examine the progress of the disease in the past week, content review of previous Session and how to do household assignments. The second part of implementation of cognitive therapy and Part III contains a short conclusion of Session,answering the patient's questions and providing home assignments. Session ninth includes a general conclusion; This Session will discuss the process of treatment, the patient's progress and problems during therapy. Also, an explanation is given about the relapse prevention (Whittal, Woody \& Rachman, 2009).

\section{Exposure Therapy}

First Session include gathering information needed for treatment planning, establishing a good relationship with the patient, the patient beliefs about OCD exploration and perceived consequences. The treatment program: Treatment program consisted of 10 Session for 60 minutes in 3 days a week which will run for 3 weeks. Each session 10 minutes is spends to review household homework and behaviors of the previous day, 15 minutes is spents for imaginary exposure, and 25 minutes is spents for in vivo exposure, 10 minutes later the next day is spend household tasks. 1 - At the start of the meeting, treatment plan will be shared with the patient. The therapist should be careful in responding and avoid unnecessary report of the patient. Of course the message does not pass the exposure to be risky exercise. 2Practice imaginary of exposure: Each session will be conducted before in vivo exposure and is often used as an introduction for in vivo exposure. During the imaginary exposure patient sits in a comfortable chair and he/she will be given the following instructions: "Today you will illustrate this scene, close your eyes in order to be distracim. Please try to visualize the scene completely and clearly, imagine in a way that you are experiencing it now. Every few minutes you were asked to rank the amount of anxiety on a scale of 0 to 100 . Please reply quickly and do not leave visualize. 3 - In vivo exposure. 


\section{RESULTS}

Table 1. Demographic characteristics of participants in the Whittal cognitive therapy, exposure therapy and control groups.

\begin{tabular}{|c|c|c|c|c|c|c|c|c|c|c|}
\hline \multirow{2}{*}{$\begin{array}{c}\text { Treat- } \\
\text { ment } \\
\text { groups }\end{array}$} & \multicolumn{4}{|c|}{ Education } & \multicolumn{2}{|c|}{ Marital } & \multicolumn{2}{|c|}{ Gender } & \multirow{2}{*}{$\begin{array}{c}\text { Mean } \\
\text { Age }\end{array}$} & \multirow{2}{*}{$\begin{array}{c}\text { Mean } \\
\text { Duration } \\
\text { of OCD }\end{array}$} \\
\hline & Guidance & $\begin{array}{c}\text { High } \\
\text { school }\end{array}$ & Diploma & Collegiate & Single & Married & Female & Male & & \\
\hline Cognitive & 5 & 3 & 4 & 3 & 6 & 9 & 9 & 6 & 28.60 & 5.93 \\
\hline Exposure & 4 & 5 & 4 & 2 & 5 & 10 & 7 & 8 & 28.53 & 5.66 \\
\hline Control & 5 & 5 & 3 & 2 & 5 & 10 & 8 & 7 & 30.93 & 4.86 \\
\hline
\end{tabular}

Table 2. Mean and standard deviation subscales of OCD.

\begin{tabular}{cccccc}
\hline Treatment & Test & $\begin{array}{c}\text { Check out } \\
\text { M (SD) }\end{array}$ & $\begin{array}{c}\text { Washing } \\
\text { M(SD) }\end{array}$ & $\begin{array}{c}\text { Slowness } \\
\text { M(SD) }\end{array}$ & $\begin{array}{c}\text { Obsessive } \\
\text { doubts } \\
\text { M(SD) }\end{array}$ \\
\hline Cognitive & Pre-test & $7.86(0.91)$ & $9.73(1.03)$ & $6.26(0.79)$ & $5.66(0.97)$ \\
& Post-test & $2.73(0.79)$ & $4.35(1.59)$ & $2.06(0.96)$ & $2.26(0.88)$ \\
Exposure & Pre-test & $7.73(0.88)$ & $9.46(0.91)$ & $6.15(0.75)$ & $6.00(0.92)$ \\
& Post-test & $5.26(0.70)$ & $7.06(0.96)$ & $4.14(0.77)$ & $3.80(0.86)$ \\
Control & Pre-test & $8.00(0.92)$ & $9.66(0.97)$ & $6.13(0.74)$ & $6.06(0.70)$ \\
& Post-test & $7.73(0.88)$ & $8.73(0.59)$ & $5.80(0.86)$ & $5.13(0.63)$ \\
\hline
\end{tabular}

Table 3. Levene's Test of Equality of Error Variances.

\begin{tabular}{ccccc}
\hline Variables & F & Df1 & Df2 & sig \\
\hline Check out & 2.09 & 2 & 42 & 0.13 \\
Washing & 5.35 & 2 & 42 & 0.25 \\
Slowness & 1.50 & 2 & 42 & 0.23 \\
Obsessive doubts & 0.91 & 2 & 42 & 0.40 \\
\hline
\end{tabular}

As can be seen in Table 3, test (F) is not significant for four variables Check out, Washing, Slowness and Obsessive doubts $(\mathrm{P} \geq 0.05)$. This indicates that these variables are equal variance among the participants (Whittal cognitive therapy, exposure therapy and control groups).

Table 4. The credit information indexcomponents of variance to test the validity of OCD.

\begin{tabular}{cccccc}
\hline & Value & F & Hypothesis df & Error df & Sig. \\
Pillai's trace & 0.98 & 8.65 & 8.00 & 72.00 & .00 \\
Wilks' lambda & 0.06 & 25.38 & 8.00 & 72.00 & .00 \\
Hotelling's trace & 13.51 & 57.44 & 8.00 & 68.00 & .00 \\
$\begin{array}{c}\text { Roy's largest } \\
\text { root }\end{array}$ & 13.46 & 80.17 & 4.00 & 36.00 & .00 \\
\hline
\end{tabular}


As can be seen in Table 4 Wilks' lambda value is equal to $0 / 06$, which is significant at the level ( $\mathrm{P} \geq 0.01$ ). This means that there is a significant difference between the Whittal cognitive therapy, exposure to therapy and control groups in terms of four variables check out, Washing, Slowness and Obsessive doubts. To determine what type of treatment is more effective on obsession components, multi-way analysis of covariance table is used, which is presented in Table 5.

Table 5. Multivariate analysis of covariance's Whittal cognitive therapy and exposure therapy on subscale's OCD.

\begin{tabular}{ccccccc}
\hline Variables & Source & $\begin{array}{c}\text { Type III } \\
\text { Sum of } \\
\text { Squares }\end{array}$ & df & $\begin{array}{c}\text { Mean } \\
\text { Square }\end{array}$ & F & Sig \\
\hline Check out & Group & 171.78 & 2 & 89.85 & 143.28 & 0.001 \\
& Pre-test & 0.14 & 2 & 0.14 & 0.24 & 0.27 \\
Washing & Group & 124.21 & 2 & 62.10 & 46.25 & 0.001 \\
& Pre-test & 0.59 & 2 & 0.59 & 0.99 & 0.21 \\
Slowness & Group & 103.07 & 2 & 51.53 & 71.79 & 0.001 \\
& Pre-test & 3.41 & 2 & 3.41 & 4.76 & $0 / 19$ \\
Obsessive & Group & 58.10 & 2 & 29.05 & 46.48 & 0.001 \\
doubts & Pre-test & 0.53 & 2 & 0.53 & 0.85 & 0.13 \\
\hline
\end{tabular}

As can be seen in Table 5 with the effects of pre-test control, Whittal cognitive therapy and exposure therapy impact on subscales OCD $(\mathrm{P} \leq 0.01)$. To determine whether there are differences between the groups, the least significant difference test has been used.

Table 6. Results of the least significant difference test between the three groups on OCD subscales.

\begin{tabular}{|c|c|c|c|c|c|}
\hline Dependent Variable & (I) group & (J) group & $\begin{array}{c}\text { Mean Difference } \\
\text { (I-J) }\end{array}$ & Std. Error & Sig \\
\hline \multirow[t]{6}{*}{ Check out } & \multirow[t]{2}{*}{ Cognitive } & Exposure & -2.45 & .29 & .000 \\
\hline & & Control & -4.89 & .28 & .000 \\
\hline & \multirow[t]{2}{*}{ Exposure } & Cognitive & 2.45 & .29 & .000 \\
\hline & & Control & -2.44 & .28 & .000 \\
\hline & \multirow[t]{2}{*}{ Control } & Cognitive & 4.89 & .28 & .000 \\
\hline & & Exposure & 2.44 & .29 & .000 \\
\hline \multirow[t]{6}{*}{ Washing } & \multirow[t]{2}{*}{ Cognitive } & Exposure & -2.51 & .43 & .758 \\
\hline & & Control & -4.14 & .43 & .000 \\
\hline & \multirow[t]{2}{*}{ Exposure } & Cognitive & 2.51 & .43 & .758 \\
\hline & & Control & -1.63 & .42 & .000 \\
\hline & \multirow[t]{2}{*}{ Control } & Cognitive & 4.14 & .43 & .000 \\
\hline & & Exposure & 1.63 & .42 & .000 \\
\hline \multirow[t]{5}{*}{ Slowness } & \multirow[t]{2}{*}{ Cognitive } & Exposure & -1.13 & .31 & .001 \\
\hline & & Control & -3.73 & .31 & .000 \\
\hline & \multirow[t]{2}{*}{ Exposure } & Cognitive & 1.13 & .31 & .001 \\
\hline & & Control & -2.60 & .31 & .000 \\
\hline & Control & Cognitive & 3.73 & .31 & .000 \\
\hline
\end{tabular}




\begin{tabular}{lccccc}
\hline \multirow{3}{*}{ Obsessive doubts } & & Exposure & 2.60 & .31 & .000 \\
& \multirow{4}{*}{ Cognitive } & Exposure & -1.20 & .31 & .000 \\
& & Control & -2.86 & .31 & .000 \\
& \multirow{4}{*}{ Exposure } & Connitive & 1.20 & .31 & .000 \\
& & Control & -1.66 & .31 & .000 \\
& & Cognitive & 2.86 & .31 & .000 \\
& & Exposure & 1.66 & .31 & .000 \\
\hline
\end{tabular}

\section{CONCLUSION}

The aim of this study was investigating of the efficacy of the Cognitive and Exposure therapy on the treatment of obsessive- compulsive disorder. Results of multivariate analysis of covariance and least significant difference test showed that Whittal cognitive therapy and exposure therapy compared to control group have been effective on improving OCD types. This result is consistent with findings of Vitaly, 2009, Vitaly, Rabchavvd and Woody, 2010; Baloch and Kabdv, 2010; Vitaly and Sheila, 2010; Fva and Kzak, 2003; Bramvvtyz, 2006, Franklin and Fva, 2011; Merlot and Duke, 2007, who showed that Whittal cognitive therapy and exposure therapy have been effective on improving OCD types. The explanation it can be said that OCD patients are uncommon and have too much negative expect about the results. (For example, they think in compulsive washing, touching of waste containers they become sick and will die). Moreover, they exagerate negative consequences of various actions (For example, if you start to feel lost when driving, or the disks will encounter something, they think they have struck someone).

Thus, cognitive therapy actually works on automatic negative thoughts so that they can adjust and reduce the anxiety caused by these thoughts. Some cognitive theoreticians believe that unwanted and intrusive thoughts become obsessive thoughts that when the person interruptions and unwanted will evaluate them traumatic and consider themselves to beresponsible. This assessment leads to increased anxiety and guilt and consequently, person doesavoidance behaviors to reduce anxiety. Key factor that cognitive therapy focuses on is negative thoughts or interpretations which are the results of annoying and unwanted experiences. Examples of these thoughts are including: "I forgot to check the stove; I could get my hands once I get sick, or half the time they spend brushing." In Whittal cognitive therapy, "The third session of the Seventh " emphasizing the modified negative thoughts and In fact, modified Automatic negative thoughts, modified negative assessment, interfering thoughts and responsibilities extremist causes the person not to interpret imposed thoughts as harmful. Whittal (2003) believes that in order to help patients with washing obsession, the patient should understand his irrational thoughts such as: "If I can touch the trash containers, I get sick and perhaps die" or "For my hand to be really clean, it is necessary to wash them several times." Therapist in cognitive therapy helps the patient to modify these irrational thoughts and achieve a more accurate perception of threat. "The Touching containers of waste, will not hurt me" or" for cleaning my hands, once washing is enough." When the patient was able to replace negative thoughts and irrational to rational thoughts, In fact, anxiety is reduced (Turner, 2006). In the explanation of the effect of exposure therapy we can say that this method can prompte anxiety associated with obsession.

The purpose of this approach is that in order to reduce anxiety reponses, if patients should exposure to his fear. This exposure, executed as a hierarchy, can be at the level of imagination and reality. After that, the patient's anxiety level increased by imaginary exposure 
and in vivo exposure, he will be encouraged to avoid from obsession ritualistic behavior. Thus raising patient's anxiety as imaginary or actual causes the patient to reduce anxiety and compulsive behaviors are reduced (Storch, Lisa and Merlo, 2006). Foa et al (2000) analyzed eighteen-controlled study and achieved the conclusion that after implementation of exposure method morbidly symptoms disappeared in $51 \%$ of patients with obsession or have improved considerably. In order to justify Whittal cognitive therapy is more effective than exposure therapy, it can be said that cognitive therapy works on Cognition irrational obsessive patients and can reduce or eliminate the unreasonable Cognition, In fact, patients will have more control. Also, Whittal cognitive therapy reduced negative cognitive in patients with OCD (Whittal, 2009). In contrast, exposure therapy may not be able to stop anxiety in obsessive people all the time.

\section{References}

[1] Abramowitz, J. S. (2006). Effectiveness of psychological and pharmacological treatment for obsessive- compulsive disorder: A guantitative review. Journal of consulling and clinical psychology, 65, 44-52.

[2] American Psychiatric Association (2000). Diagnostic and statistical manual of mental disorders (4th ed.). Washington, DC: Author.

[3] Amparo Bellocha, Elena Cabedob (2010). Cognitive therapy for autogenous and reactive obsessions: Clinical and cognitive outcomes at post-treatment and 1-year follow-up, Journal of Anxiety Disorders 24 573-580, doi:10.1016/j.janxdis.2010.03.017.

[4] Foa E. B., Steketee G. S., Milby J. B. (2000) Differential effects of exposure and response prevention in obsessive-compulsive washers. J Consult Clin Psychol 48:71-79.

[5] Foa, E. B., Kozak, M. J (2003). Emotional processing of fear: Exposure to corrective information. Psychological Bulletin, 44, 35-99.

[6] Foa E. B., Kozak M. J., Steketee G. S., McCarty, P. R. (2003). Imipramine and behavior therapy in the treatment of depressive and obsessive-compulsive symptoms. Immediact and long term effect. British Journal of Clinical Psychology, 31, 249-292.

[7] Franklin, M. E; Foa, E. B (2002). Cognitive behavior treatments for obsessive compulsive disorder.

[8] Gunter R. W, Whittal M. L. (2010). Dissemination of cognitive-behavioral treatments for anxiety disorders: Overcoming barriers and improving patient access. Clinical Psychology Review, 30(2): 194-202.

[9] Merlo, L. J., Duke, D. (2007). Family-based cognitive behavioral therapy for pediatric Obsessive-compulsive disorder: Comparison of intensive and weekly approaches. Journal of Clinical Child and Adolescent Psychiatry, 36, 207-216.

[10] Pinard G. (2006). The pharmacologic and psychological treatment of obsessivecompulsive disorder. Can J Psychiatry, 51(7): 405-6.

[11] Rachman, S. J; Hodgson, R. J (2002) : Obssesive and Compulsions, Englewood cliffs, N. J. Prentice-Hall.

[12] Rachman, S. J; Desilva, R. J. (2002). Obssesive and Compulsions, Englewood cliffs, N. J., Prentice-Hall, European Journal of Integrative Medicine, (3), 120-133. 
[13] Storch, Eric A., Geffken, Gary R., Merlo, Lisa J., Mann Giselle, Danny Duke B. A., Munson Melissa B. A., Adkins Jennifer, Krissten M., Grabill B. A., Goodman, Waynek M. D. (2006). Family- Based Cognitive- Behavioral therapy for pediatric obsessivecompulsive disorder: comparision of intensive and weekly approaches. Department of psychiatry.

[14] Trine Stub, Terje Alræk, Jianping Liu. (2011). Acupuncture treatment for depression-A systematic review and meta-analysis, European Journal of Integrative Medicine 3, e259-e270.

[15] Van Oppen P., Emmelkamp P. M. G., van Balkom A., van Dyck R. (2005). The sensitivity to change of measures for obsessive-compulsive disorder. J Anxiety Disord, 9: 241-248.

[16] Wells A., Cartwright-Hatton S. (2004). Does meta-cognition or responsibility predict obsessive-compulsive symptoms: a test of the metacognitive model. Clinical Psychology and Psychotherapy, 11, 137-144.

[17] Whittal Maureen L.; Woody Sheila R. ( 2010). Treatment of obsessions: A randomized controlled trial, Behaviour Research and Therapy, 48(4), 295-303.

[18] Whittal, M. L; Thorderson, D. S; M C lean, PD. (2005). Treatment of obsessivecompulsive disorder:cognitive behavior therapy,exposure and response prevention. Behavior Research and Therapy, 43, 1559-1570.

[19] Whittal, Maureen. L. Robichaud, Melisa; Woody, Sheila. R. (2009). Cognitive Treatnent of Obsession: Enhancing Dissemination with video components. University of British Columbia,197(8): 619-622.

[20] Whittal Maureen L; Robichaud Melisa; Woody Sheila R. (2010). Cognitive Treatnent of Obsession: Enhancing Dissemination with video components. University of British Columbia. Journal of behavior (5): 1234-1244.

[21] Whittal, Maureen. L; Woody, Sheila. R; Mclean, Peter. D; Rachman, S. J; Robichaud, Melisa. (2009). Treatment of obsessions:A randomized controlled trial. University of British Columbia Hospital, Vancouver, BC, Canada V6T 2A1. 